\title{
Factors Supporting an Information Technology Management: Teachers in Primary Schools in Thailand
}

\author{
https://doi.org/10.3991/ijet.v12i04.6654 \\ Daoprakai Raso \\ King Mongkut's Institute of Technology Ladkrabang, Bangkok, Thailand \\ daoprakai@gmail.com \\ Pariyaporn Tungkunanan \\ King Mongkut's Institute of Technology Ladkrabang, Bangkok, Thailand \\ Pariya2511@gmail.com \\ Abhichat Anukulwech \\ Chonburi Technical College, Chonburi, Thailand \\ abhichat_a@hotmail.com
}

\begin{abstract}
The objectives of this research were (1) to study the authentic situation of the Information Technology Management of Teachers in Primary Schools in Thailand (2) to study the factors supporting the Information Technology Management of Teachers in Primary Schools in Thailand.

The sample group consisted of 165 teachers, teaching in primary schools under the office of the basic education commission (OBEC) in Thailand in 2016 The samples were taken using Multi - Stage Sampling randomized technique. Data were collected by using questionnaire include 101 questions from 6 factors in which the questionnaires were approved content validity from experts at level of 0.95 and 0.97 , respectively. The statistics were used to analyse the data as follows: mean (M), standard deviation (S.D), and Stepwise Multiple Regression Analysis. The study revealed that (1) the authentic situation of the Information Technology Management was found at "very often" level for the operation of the information technology management $\bar{x}=4.09$ and S.D. $=0.47$ and (2) the factors that support the Information Technology Management consisting of the hardware factors and the people factor. The percentage was 28.80 and 32.70 consecutively, and shown the raw score and standard score was found from this formula $\dot{Y}=1.989+.322(\mathrm{X} 1)+.178(\mathrm{X} 6) \dot{\mathrm{Z}}=.363(\mathrm{X} 1)+$ $.262(\mathrm{X} 6)$.
\end{abstract}

Keywords - Information Technology Management, Factors supporting the Information Technology Management, School management

\section{$1 \quad$ Introduction}

An information system (IS) can be defined technically as a set of interrelated components that collect (or retrieve), process, store, and distribute information to support 
decision making and control in an organisation. In addition to support decision making, coordination, and control, information systems may also help managers and workers analyse problems, visualize complex subjects, and create new product. [1] And Turban, Leidner, McLean, Wetherbe said IS as one that collects, processes, stores, analyzes, and disseminates data and information for a specific purpose. [2 ]

The information that arrived 'bottom up' was trusted more than information provided by external sources. If information became available from uncertain sources or was not reliable at first sight, it was thoroughly scrutinized for its credibility and robustness before being accepted by the departments responsible for supplying information to the board [3]. Recent Information Technology Trends as a user of computers and communication devices, you are well aware that improvements in computer hardware, software, and communication networks have been dramatic and frequent over the past decade in particular [4]

The Ministry of Education in Thailand focused on the importance of educational information, because such information can be useful for education management. For example, an information system can help a director make decisions efficiently and design proper plans. [5]. Also Lukasz Grudzie'n and Adam Hamrol [6] said the Information is the main constituent of documents that make up a quality management system. The Information and Communication Technologies (ICTs) is a general term which refers to all kinds of technologies that enable users to access and manipulate information. [7]

The education report of the Research Project for Guidelines To Develop Thai Education and Preparation to the 21st Century of Office of the Education Council in 2014 resulted in a policy to use information technology and communication for education. The main idea of using technology for education system management is to build database systems for all sectors in the education system, considering the advantages and disadvantages for all participants. In addition, the information held can be used to manage or improve many processes such as those of school quality control [8] The information has increased because of the development of ICT and impact in numerous ways, especially an individual potential to achieve in the 21 st century. [9] With the rapid development of science and technology, Computer and Internet has become an indispensable tool in modern education and have brought great change in the teaching models of college education in the world. [10]

To develop quality there must be quality assurance in the management and learning processes of schools continuously improving learner quality in order to ensure that schools have a proper and efficient education system as standard. Internal quality assurance, such as the educational standards of schools, is a step of internal quality assurance of basic education issued in ministerial regulations, in the title of system, principles and steps to do education quality assurance 2010. The ministerial regulations also stated that schools for basic education must have internal quality assurance with the support and control of the head organization. Schools should hold and follow the principles and guidelines of association with communities and involved agencies, both in the state and private sectors. Management and data systems are one of eight steps involving internal quality assurance of schools, allowing schools to see the quality of their education management. Also, schools can recheck whether they meet the 
goal or education standard of the academy. They can then improve their management properly and continuously [11]. Isabel Guitart, Jordi Conesa [ 12] said The business intelligence system for teachers is composed of Data warehouse that stores the data needed for decision-making of the teachers. The data comes from different information systems (academic, virtual classroom, learning resources, classroom messages, etc) and are of different types (structured or unstructured). And the Changing Trend of ICT usage among School Teachers Based on our earlier assumptions, that the available facilities (computer labs and internet connection) provided to schools and the computer training provided to teachers, we expect to find increasing use of ICT in teaching among school teachers. [13]

The above details show that information technology management are very important for teachers in the primary school to education management, and that improved information systems can help schools operate education management well and efficiently.

\section{Objective}

1. To study the authentic situation of the Information Technology Management of teachers in primary schools in Thailand.

2. To study the factors supporting information technology management of teachers in primary schools in Thailand.

\section{Conceptual Framework}

In this study, the researcher follows the 2 concept of the Information Technology Management were 1) the Information System Activities, and 2) the factors an information system

1. The researcher follows the Information System Activities of James A. O'Brien and George M. Marakas [14] as follows:

(a) Input is an optical scanning of bar-coded tags on merchandise.

(b) Processing is a Calculating employee pay, taxes, and other payroll deductions.

(c) Output is a producing reports and displays about sales performance.

(d) Storage is a maintaining records on customers, employees, and products.

(e) Control is a generating audible signals to indicate proper entry of sales data.

2. The research follows the factors of an information system of Efraim TurBan and Linda Volonino [15] as research framework which includes 6 factors as follows:

(a) Hardware is a set of devices such as processor, monitor, keyboard, and printer. Graphical user interfaces, which are called GUI, accepted data and information that are then processed by central processing units (CPUS), stored in databases, and displayesd on screens.

(b) Software is a set of applications (apps) or program that instruct the hardware to process data or other inputs such as voice commands.

(c) Data is an essential part processed by the system and, if needed, stored in a data-base or other storage system. 
(d) A network is a telecommunication system connecting hardware that is wired, wireless, or a combination.

(e) Procedure are the set of instructions about how to combine the above components in order to process information and generate the desired output.

(f) People are those individuals who work with the system, interface with it, or use its output.

\section{$4 \quad$ Methodology}

\subsection{Population and Samples}

Population: 2,192 teachers, teaching in 1,096 government primary schools under the OBEC, inspection area 3 included in 9 provinces in Thailand.

Samples: 165 teachers, teaching in 1,096 government primary schools under the OBEC, inspection area 3 included in 9 provinces in Thailand. Calculate by using $\mathrm{G}^{*}$ power program [16]. The process to find the size of sampling groups in 4 steps as follows; 1) F-test with selected sampling group 2) selected kinds of test with the Linear multiple regression: Fixed model, R2 deviation from zero 3) indicated the effect size 4) supply data to $\alpha=.05 ;(1-\beta)=.95$; predict variable number $=6$. The suitable sampling groups at least 120 people. However, this research collected the data from 165 people, for significant administration and to prevent sampling group missing, It is necessary to adjust the sample size to fit the research.

\subsection{Variables}

1. Independent Variable (Predictor) : 1) Hardware 2) Software 3) Data 4) Network 5) Procedure and 6) People

2. Dependent Variable (Criterion variable) 1) Input 2) Processing 3) Output 4) Storage and 5) Control

\subsection{Research Tools}

The research tools was the questionnaires in 3 parts: 1) the general information of respondents contains 4 items, step 2) to study the authentic situation of the Information Technology Management of Teachers in Primary Schools in Thailand. The questionnaire had reliability at 0.95 . It consisted of 42 questions which were: Input 9 questions, Processing 6 questions, Output 7 questions, Storage 5 questions, and Control 15 questions. And 3) to study the factors supporting the Information Technology Management of Teachers in Primary Schools in Thailand. The questionnaire had reliability at 0.97 . It consisted of 59 questions which were: Hardware 9 questions, Software 9 questions, Data 11 questions, Network 10 questions, Procedure 10 questions, and People 10 questions.

The Item-Objective Congruence (IOC): The research tools used was a questionnaire with The Item-Objective Congruence (IOC) which was used to find the content 
validity. In this process, the questionnaire was checked by five experts in their related fields. The IOC was used to evaluate the items of the questionnaire based on the score range from -1 to +1 .

- Congruent $=+1$

- Questionable $=0$

- Incongruent $=-1$

The items that had scores lower than 0.5 were revised or eliminated. On the other hand, the items that had scores higher than or equal to 0.5 were retained. In this research the Item Objective Congruence $(\mathrm{IOC})=0.60-1.00$.

Reliability: The try-out process of 30 questionnaires, reliability of the questionnaire was determined to ensure that the responses collected through the instrument were reliable and consistent. The reliability value was calculated by using Cronbach's alpha [17] to ensure internal consistency within the items. George and Mallery [18] illustrated the value of Coefficient Cronbach's Alpha In general, a score of more than 0.7 is considered acceptable, although some authors suggest higher values of 0.90 0.95 should be the norm [19]. From even the most stringent criteria of Cronbach's Alpha [17], the study's questionnaires were deemed to be highly reliable as the score was 0.971 .

\subsection{Data Collection}

The data were collected in 2016 by questionnaires out to participants by mail and attached the envelope addressed of the researcher for the participants sent back. The participants evaluate the authentic situations of the Information Technology Management of teachers'. The scales in are as follows: $1=$ never, $2=$ rarely, $3=$ sometimes, 4 $=$ often, 5 = always

The participants evaluate the factors supporting the Information Technology Management of teachers'. The scales in are as follows: $1=$ strongly disagree , 2 = disagree , 3 = undecided , $4=$ agree, $5=$ strongly agree

Part 1) the general information of respondents contains 5 items, part 2) to study the authentic situation of the Information Technology Management of Teachers, and part 3) to study the factors supporting the Information Technology Management.

\subsection{Data Analysis}

1. The data of level of teachers' authentic situation of information technology management were analysed with descriptive statistics; Mean (M) and Standard Deviation (S.D).

2. The data to find the factors supporting the Information Technology Management were analyse with the Stepwise Multiple Regression Analysis. 


\section{Results}

The questionnaires were received return amount 144 sample (87.27\%) from 165 people.

\subsection{General information of participants}

Table 1. General information of participants

\begin{tabular}{|l|l|l|}
\hline \multicolumn{1}{|c|}{ General Infoemation } & \multicolumn{1}{c|}{ Number } & Percentage \\
\hline Sex & 69 & \\
Female & 75 & 47.9 \\
male & 43.1 \\
\hline Education & 91 & 29.9 \\
Bachelor & 10 & 63.2 \\
Master & & 6.9 \\
Doctor & 6 & 4.2 \\
\hline Experience & 24 & 16.7 \\
five yrs & 38 & 26.4 \\
$5-10$ yrs & 8 & 5.6 \\
$11-15$ yrs & 68 & 47.2 \\
$16-20$ yrs & & \\
more than 21 & 21 & 14.6 \\
\hline School size & 67 & 46.5 \\
Small & 30 & 20.8 \\
Medium & 26 & 18.1 \\
Big & Large & \\
\hline
\end{tabular}

From Table 1, General information of participants the questionnaires were answered by 144 participants from 4 items are as follow:

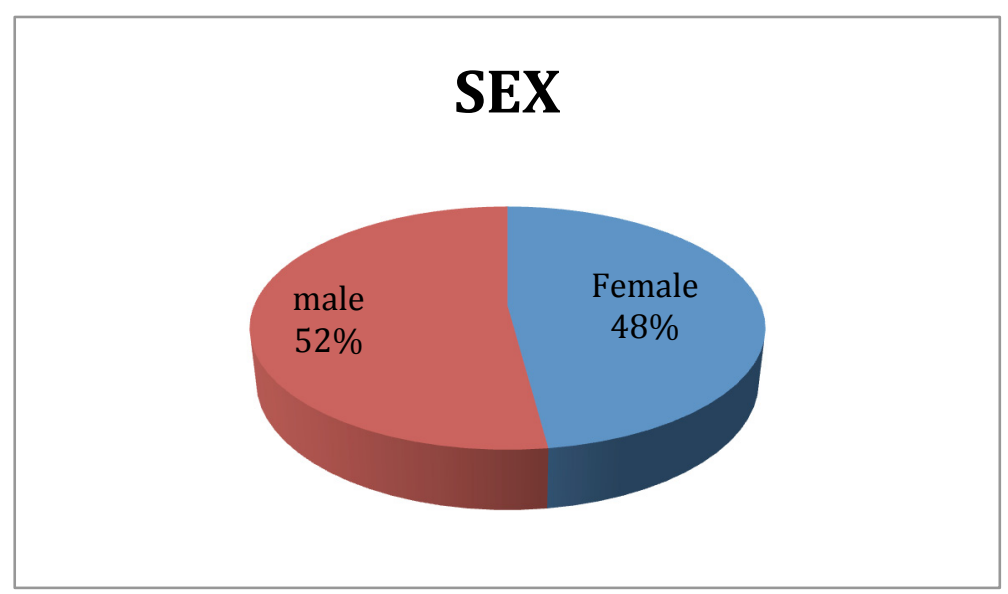

Fig. 1. The percentage of teachers' sex

Sex : 69 from female teachers $=47.9 \%, 75$ from male teachers $=52.1 \%$ 


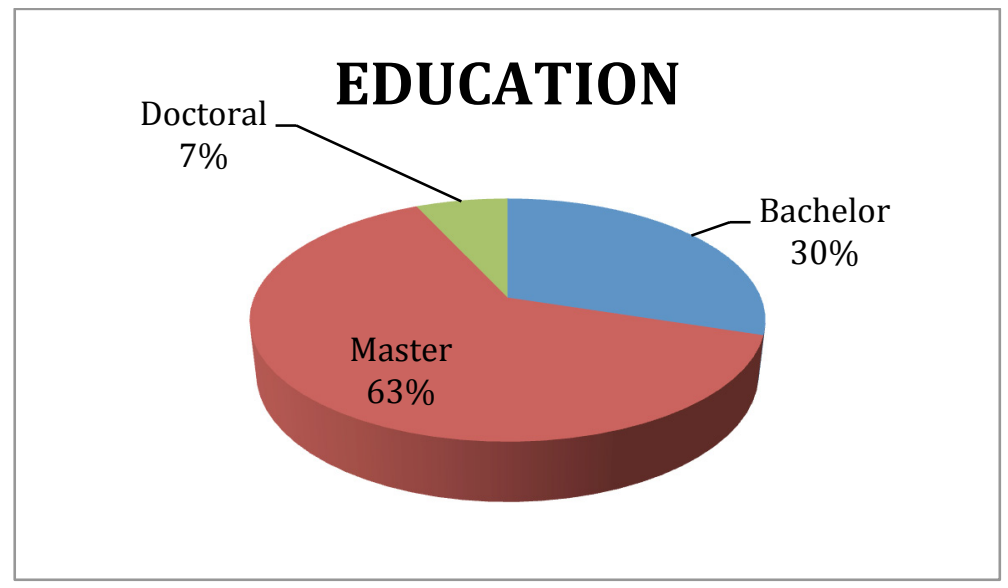

Fig. 2. The percentage of teachers' education

Education $=43$ from Bachelor Degree teachers $=29.9 \%, 91$ from Master Degree teachers $=63.2 \%, 10$ from Doctoral Degree teachers $=6.9 \%$

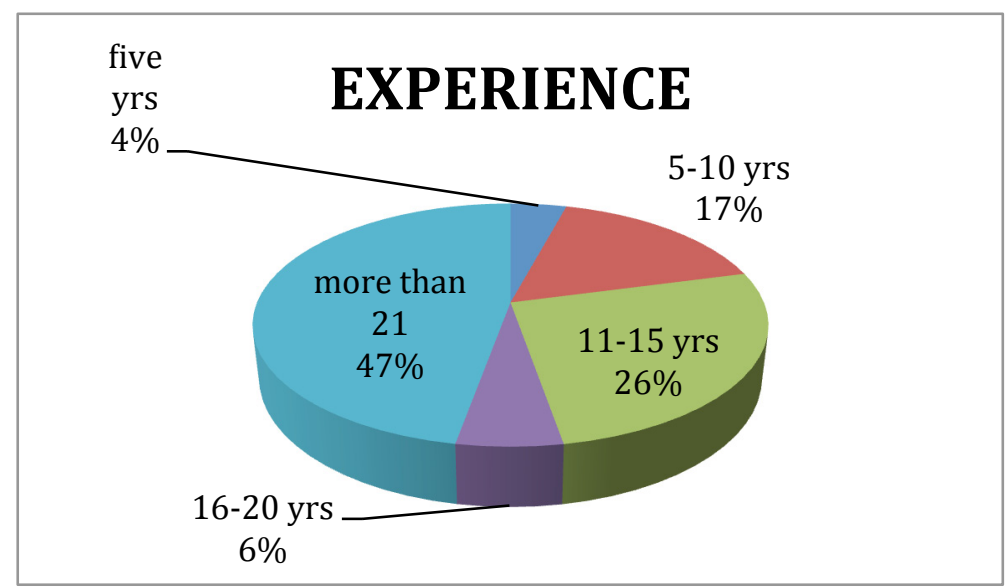

Fig. 3. The percentage of teachers' experience

Experience $=6$ from less than 5 experience years teachers $=4.2 \%, 24$ from $5-10$ experience years teachers $=16.7 \%, 38$ from $11-15$ experience years teachers $=$ $26.4 \%, 8$ from $16-20$ experience years teachers $=5.6 \%, 68$ from more than 21 experience years teachers $=47.2 \%$. 


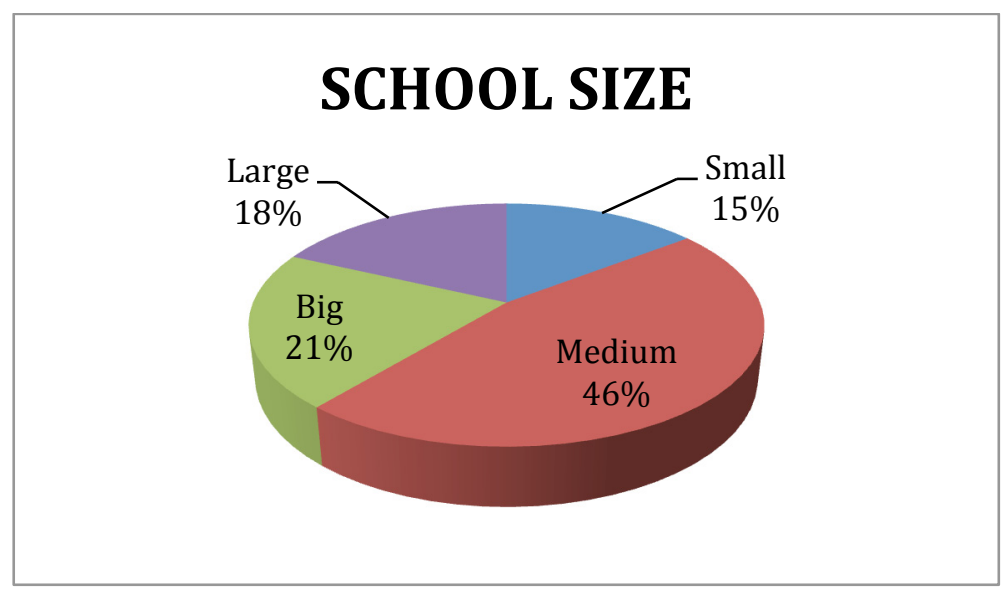

Fig. 4. The percentage of teachers' school size

School size (according to number of students, divided by OBEC in Thailand) $=21$ teachers from small school $=14.6 \%, 67$ teachers from medium school $=46.5 \%, 30$ teachers from big school $=20.8 \%, 26$ teachers from Large school $=$ $18.1 \%$.

5.2 Authentic situation of Teachers' of information technology management of Teachers in Primary Schools in Thailand.

Table 2. shows authentic situation of Teachers' of information technology management of Teachers in Primary Schools in Thailand.

\begin{tabular}{lccccc}
\hline & List & & S.D. & Levels of operation \\
\hline 1. Input & & 4.21 & .44 & often & \\
2. Processing & & 4.05 & .60 & often & \\
3. Output & & 4.05 & .56 & often & \\
4. Storage & & 4.09 & .60 & often & \\
5. Control & & 4.07 & .45 & often & \\
\hline & Mean & $\mathbf{4 . 0 9}$ & $\mathbf{. 4 7}$ & & often \\
\hline
\end{tabular}

From the table 2, it was found that the teacher in government primary school in Thailand had "often" level for the operation of the information technology management $=4.09$ S.D. $=0.47$, the input process was $=4.21$, S.D. $=0.44$, the processing process was $=4.05$, S.D. $=0.60$, and the output process was $=4.05$, S.D. $=0.56$.

5.3 The result of the factors supporting the information technology management as shown in the table $3-5$. 
Paper-Factors Supporting an Information Technology Management: Teachers in Primary Schools in ...

Table 3. The Results of Multi- Collinearity between the variables

\begin{tabular}{lcc}
\hline & Variables & Collinearity \\
& Tolerance & VIF \\
\hline Hardware (x1) & .280 & 3.572 \\
Software (x2) & .227 & 4.407 \\
Data (x3) & .265 & 3.768 \\
Network (x4) & .194 & 5.147 \\
Procedure (x5) & .246 & 4.067 \\
People (x6) & .338 & 2.956 \\
\hline
\end{tabular}

From the table 3 was found the statistics in variables not correlation with the Multi collinearity, because the value does not exceed 1 Tolerance and VIF not exceed 10.

Table 4. The results of predicting equation with stepwise Multiple Regression Analysis

\begin{tabular}{lccccc}
\hline $\begin{array}{c}\text { The sequence equation } \\
\text { of prognostic factors. }\end{array}$ & $\mathbf{R}$ & $\mathbf{R 2}$ & R2 change & F change & $\begin{array}{c}\text { Sig. } \\
\text { F change }\end{array}$ \\
\hline Hardware (X1) & .537 & .288 & .288 & $57.567^{*}$ & .000 \\
People (x6) & .572 & .327 & .038 & $8.022^{*}$ & .005 \\
\hline
\end{tabular}

From table 4 was found the factor predicting equation No. 1, the hardware factors (X1) was factor supporting in a the information technology management with the statistics significant at .05 , the prediction coefficient $\left(\mathrm{R}^{2}\right)=2.88$ that showed the hardware factors supporting the information technology management 28.80 percentage and the factor predicting equation No. 2, the People (x6) was the factors supporting the information technology management with the statistics significant at .05 , the prediction coefficient $\left(\mathrm{R}^{2}\right)=.327$ that showed the People factor supporting the information technology management in 32.70 percentage, two factors cooperated to support the information technology management in the primary schools in Thailand.

Table 5. indicated the correlation coefficient Stepwise Multiple Regression Analysis in predicted the factors supporting information technology management

\begin{tabular}{lccccc}
\hline \multicolumn{1}{c}{ Variables } & b & SE $_{\mathbf{b}}$ & $\boldsymbol{\beta}$ & t & Sig \\
\hline Hardware (X1) & .322 & .082 & .363 & 3.919 & .000 \\
People (x6) & .178 & .063 & .262 & 2.832 & .005 \\
\hline SE & & & &
\end{tabular}

$\mathrm{SE}_{\text {est }}=.264$

a $\quad=1.989$

Durbin-Watson $=1.910$

* sig. .05

From table 5 was found the Hardware factor and the People factor could support the information technology management of teachers in government primary schools in Thailand (y) with Statistic significant 0.00 and 0.005 , the coefficient Multiple Regression in raw score (b) 0.322 and 0.178 and the coefficient Multiple Regression in standard score (B) 0.363 and 0.262 . 
For the Durbin-Watson was the test statistic of an error free which the condition for the regression analysis. The Durbin-Watson was 1.910 , higher than 1.5 that indicate it an error free. The predict equation in the factors supporting the information technology management of teachers in government primary schools in Thailand in the raw score as follows;

$$
\dot{\mathbf{Y}}=1.989+.322(\mathrm{X} 1)+.178(\mathrm{X} 6)
$$

The equation of Multiple Regression Analysis that indicated the if increases 1 unit of the hardware factor (X1) and the people factor (x6) in the affected the factors supporting the information technology management of teachers in government primary schools in Thailand were increased 0.500 unit.

The Prediction equation in factors supporting the information technology management of teachers in government primary schools in Thailand in the standard score as;

$$
\dot{Z}=.363(\mathrm{X} 1)+.262(\mathrm{X} 6)
$$

From the Multiple Regression equation to indicate the hardware factor (X1) and the people factor (X6) ) affected the factors supporting the information technology management of teachers in government primary schools in Thailand were increased in 0.625 unit as per the Figure 5.

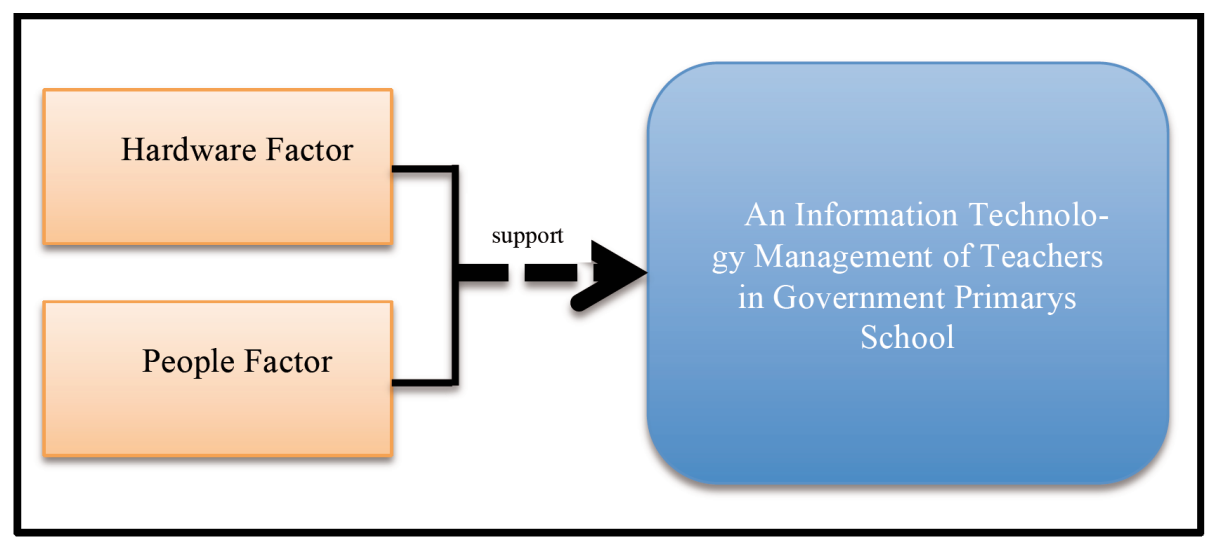

Fig. 5. The hardware factor and the people factor were supporting the information technology management of teachers in government primary schools in Thailand.

\section{Discussion}

1. To study the authentic situation of the Information Technology Management of teachers in primary schools in Thailand was found that the teacher in government primary school in Thailand had "often" level for the operation of the information technology management $=4.09$ S.D. $=0.47$. , the input process was $=4.21$, S.D. $=$ 0.44 , the processing process was $=4.05$, S.D. $=0.60$, and the output process was $=$ 4.05 , S.D. $=0.56$. The findings shows that teacher needs improved in Information 
Technology Management in the process of Processing and Output of the data. According to the Information System Activities of James A. O'Brien and George M. Marakas [14] consisted of 1) Input, 2) Processing, 3) Output, 4) Storage, and 5) Control. These all Activities in the Information System should perform with completely. The reasons can be explained that the two process the Information Technology Management that had least done because of the result can be that the teachers lacked of the skill in technology or efficiently information technology. The findings also relate to the study of Garba, Byabazaire and Busthami [13] that Malaysian teachers do not integrate ICT with other subjects. Their learning management still focuses on teacher centre rather than student centre. These result let we know the authentic situation of the Information Technology Management of teachers in primary schools in Thailand. After this we will push the teachers work in all activities of information system for successful in our jobs.

2. To study the factors supporting information technology management of teachers in primary schools in Thailand were the hardware factor and the people factor. It can be predicted because of the following reasons:

- The hardware factor of information technology management could show the readiness for the teacher of schools, in term of information technology infrastructure such as hardware, software, and the network system, to use and support the information technology management efficiently. Additionally, the readiness and efficiency of the personnel in using information technology is very important for management information system development, as per Efraim TurBan and Linda Volonino's framework [15] found that hardware is a set of devices such as processor , monitor, keyboard, and printer. Graphical user interfaces, which are called GUI, accepted data and information that are then processed by central processing units (CPUS), stored in databases, and displayed on screens. These very important infrastructure that will support in an information technology management. Furthermore James A. O' Brien [14]. Effy Oz [20] said The computer Equipment for Information System to support the data processing functions, different type of technologies are used. The five basic component components of the computer system within information system : Input devices introduce data into the Is, The computer processed data through the IS, Output Devices display information, storage devices store data and information, Networking device and communications lines transfer data and information over various distances. The findings also relate to the study of Hongyi Mao, Shan Liu, Jinlong Zhang, and Zhaohua Deng [21], who studied information technology resources, knowledge management capabilities, and competitive advantages in term of the moderating role of resource commitment, and found the data from 168 organizations in China provided empirical evidence that three types of IT resources (i.e., IT infrastructure, IT human, and IT relationships) positively affected knowledge management capability (KMC), which is positively related to competitive advantage; and the research of F. Al-Shahrani, H. Mohammad [22] found that he factors that affect the successful implementation of CoPs are: IT specialist role: a.Standardized teaching resources format. In addi-tion, there is a lack of a standardized teaching resources format, $b$. Responding to all feedback 
or technical issues, c. Users' needs can be met by having a developer as users ambassador, and d. IT profession must keep on leading the CoPs.. This also agrees with the research of Zain, Atan, and Idrus [23] who studied the effects of ICT in a smart school in Malaysia. The analysis of the results show the positive change of proper use of ICT in the school, and the efficiency of administrative information access and using resources in the school after the personnel receive training. Additionally, this agrees with the research of Sudarat Srima, Panita Wannapiroon and Prachyanan Nilsook [24], who studied the design of Total Quality Management Information System (TQMIS) for a model school as best practice, and found that schools that use information management systems that support internal audits of quality assurance should prepare both the technology base network and the basic equipment for internet connection.

- The people factor are the most important parts of the information technology system as per Efraim TurBan and Linda Volonino's framework [15] found that People are those individuals who work with the system, interface with it, or use its output. An information technology system will success or not it also depends on the human because the contrast between human-centered design and machine-centered design is useful in thinking about the design of technologies and work system. In human-centered design, the technology or business process is designed to make participants' work as effective and satisfying a possible. [25] The findings also relate to the research of Georgios N. Kouziokas [26], who studied the technologybased management of environmental organizations using an Environmental Management Information System (EMIS). The design and development stated that, as well as fulfilling the legal obligations of the environmental organization, this information can also be utilized in making decisions and taking measures about environmental issues, and also in sending documents and reports to the local and the governmental authorities (Ministry of the Environment, Judicial Authorities). These data are valuable for performing environmental risk assessment and for developing risk management strategies [27]. The system also manages information about protected species in the organization's jurisdiction area, including methods of monitoring and registering biodiversity in the protected area [28]. The EMIS system manages and provides information to the user, and the user manages and elaborates in information in EMIS, which must have information about human resources. These result let we know about the factors supporting information technology management of teachers in primary schools in Thailand. So we can support these two factors for teachers in their work.

\section{Suggestions}

1. The information technology management should be develop the model of the new technology management for find the greater way in order to enhance the teachers' technology skill in primary school for skills of the Information System Activities consisted of Input, Processing, Output, Storage, and Control. 
Paper-Factors Supporting an Information Technology Management: Teachers in Primary Schools in ...

2. The information technology management should be supporting and training how to manage about the factors in hardware and people in an information technology management for teachers in primary schools in Thailand.

\section{Acknowledgments}

I would like to express my sincere thanks to the special expert and others person for suggestions and all their help for my research. Including King Mongkut's Institute of Technology Ladkrabang, Bangkok, Thailand.

\section{References}

[1] Kenneth C.Laudon, Jane P. Laudon. (2009). Essential of Management Information Systems. $8^{\text {rd }}$ ed. Pearson Prentice Hall, Upper Saddle River, New Jersey 07458.

[2] Turban, Leidner, McLean, Wetherbe.(2008). Information Technology for Management Transforming Organizations in the Digital Economy. John Wiley \& Sons, Inc.

[3] Charles L. Citroen. (2011). The role of information in strategic decision-making. International Journal of Information Management. 31 (2011) 493-501. https://doi.org/10.1016/ j.ijinfomgt.2011.02.005

[4] E. Wainright Martin, Carol V. Brown, Daniel W. DeHayes, Jefferey A. Hoffer, William c. Perkins. (2005). Managing Information Technology. Pearson Education, Inc., Upper Saddle River, New Jersey, 07458.

[5] Ministry of Education.(2014).Policy of Office of the Basic Education Budget year 2015. Bangkok: Agricultural Cooperatives of Thailand.

[6] Łukasz Grudzie'n and Adam Hamro.l (2016) Information quality in design process documentation of quality management systems. International Journal of Information Management. 36 (2016) 599-606. https://doi.org/10.1016/j.ijinfomgt.2016.03.011

[7] Athanasios S. Drigas, and Georgia K. Kokkalia. ICTs and Special Education in Kindergarten. International Journal of Emerging Technologies in Learning.. Vol. 9, pp. 35-42, 2014, https://doi.org/10.3991/ijet.v9i4.3662

[8] Office of the Education Council in thailand. 2014. The reporting of determining of development to preparation to $21 \mathrm{st}$ in Thailand . [Online]. Available : http://http://www.onec.go.th/

[9] Murray, Janet. 2008. "Looking at ICT Literacy Standards Thought the Big6 Lens.” Library Media Connection. April/May 2008, 40-41.

[10] Wenting Ma. Study on the Influencing Factors on Network-based Autonomous Learning in Mechanical Engineering English. International Journal of Emerging Technologies in Learning.. Vol.30, 2016, pp.57-62, https://doi.org/10.3991/ijet.v11i03.5536

[11] Educational Testing Bureau in Thailand .(2013). The management systems and information of school according to the ministerial rules and procedures for accreditation 2010.3nd ed.. Bangkok: Agricultural Cooperatives of Thailand.

[12] Isabel Guitart, Jordi Conesa . Adoption of Business Strategies to Provide Analytical Systems for Teachers in the Context of Universities. International Journal of Emerging Technologies in Learning.. Vol. 11, pp. 34-40, 2016, https://doi.org/10.3991/ijet.v11i07.5887

[13] S. A. Garba, Y. Byabazaire and A. H. Busthami . Toward the Use of 21st Century Teaching-Learning Approaches: The Trend of Development in Malaysian Schools within the 
Paper-Factors Supporting an Information Technology Management: Teachers in Primary Schools in ...

Context of Asia Pacific. International Journal of Emerging Technologies in Learning.. Vol.10, 2015, pp.72-79. https://doi.org/10.3991/ijet.v10i4.4717

[14] James A. O' Brien, George M. Marakas: Management Information. Systems, 8th Edition, McGraw Hill, 2008.

[15] Efraim TurBan and Linda Volonino (2012) Information technology for management (international student version). John Wiley \& Sons (Asia) Pte Ltd.

[16] Franz Faul, Edgar Erdfelder,Albert-Georg Lang And Axel Buchner (2007). G*Power 3:A flexible statistical power analysis program for the social, behavioral, and biomedical sciences. Behavior Research Methods, 39 (2), 175-191. https://doi.org/10.3758/BF03193146

[17] Cronbach, L. (1951). Coefficient alpha and the internal structure of tests. Psychometrika. 16(3), pp.297-334. https://doi.org/10.1007/BF02310555

[18] George, D. and Mallery, P. (2010) SPSS for Windows Step by Step: A Simple Guide and Reference 17.0 Update. 10th Edition, Pearson, Boston.

[19] Tavakol, M. \& Dennick, R. (2011). Making sense of Cronbach's alpha. International journal of Medical Education, 2, pp.53-55. https://doi.org/10.5116/ijme.4dfb.8dfd

[20] Effy Oz .2009. Management Information Systems. $6^{\text {rd }}$ ed.International Edition. Course Technology, Cengage Learning.

[21] Hongyi Mao, Shan Liu, Jinlong Zhang, Zhaohua Deng (2016) Information technology resource, knowledge management capability, and competitive advantage: The moderating role of resource commitment. International Journal of Information Management. 36 (2016) 1062-1074. https://doi.org/10.1016/j.ijinfomgt.2016.07.001

[22] F. Al-Shahrani, H. Mohammad. Conceptual Model of Successful Educational Online Community of Practice for Kingdom of Saudi Arabia. International Journal of Emerging Technologies in Learning.. Vol.9, 2014, pp.4-10. https://doi.org/10.3991/ijet.v9i9.3864

[23] Zain, M.Z, Atan, H., \& Idrus, R.M. (2004) The impact of information and communication technology (ICT) on the management practices of Smart Schools. International Journal of Educational Development. 24 Z2X, 201-211. https://doi.org/10.1016/j.ijedudev. 2003.10.010

[24] Sudarat Srima, Panita Wannapiroon and Prachyanun Nilsook(2015). Design of total quality management information system (TQMIS) for model school on best practice. Journal of Science Direct. Procedia - Social and Behavioral Sciences 174 ( 2015 ) 2160 - 2165. https://doi.org/10.1016/j.sbspro.2015.02.016

[25] Steven Alter (2002). Information System. $4^{\text {rd }}$ ed. Pearson Education, Inc., Upper Saddle River, New Jersey, 07458.

[26] Georgios N. Kouziokas (2016) Technology-based management of environmental organizations using an environmental Management Information System (EMIS): Design and development. Environmental Technology \& Innovation 5 (2016) 106-116 https://doi.org/10.1016/j.eti.2016.01.006

[27] Lener, M., Giovannelli, V., Arpaia, S., Baldacchino, F., Benedetti, A., Burgio, G., Canfora, L., Dinelli, G., Manachini, B., Marotti, I., Masetti, A., Sbrana, C., Rastelli,V., Staiano, G., 2013. Applying an operating model for the environmental risk assessment in Italian Sites Importance (SCI) of the European Commission Habitats Directive (92/43/EEC). Bull. Insectol. 66 (2), 257-267.

[28] Danielsen, F., Balete, D.S., Poulsen, M.K., Enghoff, M., Nozawa, C.M., Jensen, A.E., 2000. A simple system for monitoring biodiversity in protected areas of a developing country. Biodivers. Conserv. 9, 1671-1705. https://doi.org/10.1023/A:1026505324342 


\section{Authors}

Daoprakai Raso is with the King Mongkut's Institute of Technology Ladkrabang, Faculty of Industrial Education, Bangkok, Thailand 10520 (daoprakai@gmail.com).

Pariyaporn Tungkunanan is associate professor with the King Mongkut's Institute of Technology Ladkrabang, Faculty of Industrial Education, Bangkok, Thailand 10520 (Pariya2511@gmail.com).

Abhichat Anukulwech is with the Chonburi Technical College, Chonburi, Thailand 20170 (abhichat_a@hotmail.com).

Article submitted 17 January 2017. Published as resubmitted by the authors 23 February 2017. 